\title{
AUDIT TEKNOLOGI INFORMASI MENGGUNAKAN FRAMEWORK COBIT 5 PADA DOMAIN DSS (DELIVER,SERVICE, AND SUPPORT) (STUDI KASUS : KONSULTAN MANAJEMEN PUSAT)
}

\author{
Ricky Perdana Kusuma \\ Sekolah Tinggi Manajemen Informatika dan Komputer CIC \\ Jl. Kesambi No. 202 Kel. Drajat Kec. Kesambi Kota Cirebon, Jawa Barat 45133 \\ e-mail: rickyperdanak@gmail.com
}

\begin{abstract}
Teknologi informasi (TI) perlu diatur agar dapat dimanfaatkan dengan baik, dimana tindakan untuk mengatur TI disebut dengan audit TI. Tujuan audit TI untuk meminimalkan terjadinya fraud dan risiko dalam sistem informasi. Standar audit yang digunakan adalah Control Objective for Information and Related Technology (COBIT) 5. COBIT 5 merupakan framework yang memiliki kedetailan standar dalam hal teknis dan operasional serta kelengkapan proses TI yang baik. Domain yang dipakai dari COBIT 5 yaitu domain DSS (Deliver, Service, and Support), dipilih karena fokus pada aspek penyampaian TI di dalam pengiriman dan layanan TI serta dukungannya terhadap proses bisnis yang berlangsung termasuk pengelolaan masalah agar keberlanjutan proses bisnis tetap terjaga. Konsultan Manajemen Pusat (KMP) merupakan satu organisasi yang mengimplementasikan TI yaitu Sistem Informasi Manajemen Kota Tanpa Kumuh (SIM KOTAKU) untuk pengendalian program Kota Tanpa Kumuh (KOTAKU) di bawah Ditjen Cipta Karya (DJCK) Kementerian Pekerjaan Umum dan Perumahan Rakyat (Kementrian PUPR). Hasil dari audit TI saat ini Capability Level yang didapat pada SIM KOTAKU di KMP yaitu Level 1, yaitu Performed Process, dan Level target yang ingin dicapai adalah Level 2 yaitu Managed Process, sehingga berdasarkan analisis kondisi existing diperlukan peningkatan aktivitas dengan rekomendasinya yaitu memaksimalkan sistem yang sudah berjalan dengan peningkatan pengelolaan permintaan layanan dan insiden serta peningkatan layanan keamanan lebih terstruktur sesuai SOP (Standar Operating Procedure) dan terdokumentasi.
\end{abstract}

Kata kunci: audit TI, COBIT 5, domain DSS, Konsultan Manajemen Pusat (KMP), Capability Level

\begin{abstract}
Abstrak
Information technology (IT) needs to be regulated so that it can be used properly, where actions to manage IT are called IT audits. The purpose of the IT audit is to minimize fraud and risk in information systems. The audit standard used is Control Objective for Information and Related Technology (COBIT) 5. COBIT 5 is a framework that has standardized details in terms of technical and operational as well as complete IT processes. The domain used from COBIT 5, namely the DSS domain (Deliver, Service, and Support), was chosen because it focuses on the aspects of IT delivery in IT delivery and services as well as its support for ongoing business processes including problem management so that the sustainability of business processes is maintained. The Central Management Consultant (KMP) is an organization that implements IT, which is a Slum City Management Information System (SIM KOTAKU) for controlling the Slum City Program (KOTAKU) under the Directorate General of Human Settlements (DJCK) of the Ministry of Public Works and Public Housing (Ministry of PUPR). The results of the current IT audit Capability Level obtained on KOTAKU SIM in KMP are Level 1, namely Performed Process, and the target level to be achieved is Level 2, namely Managed Process, so that based on the analysis of existing conditions it is necessary to increase activity with its recommendation of maximizing the system already running with improved management of service requests and incidents as well as improved structured security services according to the SOP (Standard Operating Procedure) and documented.
\end{abstract}

Keywords: IT audit, COBIT 5, DSS domain, Central Management Consultant (KMP), Capability Level

\section{Pendahuluan}

JURNAL DIGIT Vol. 9, No.1 Mei 2019 : 97 109 
Teknologi informasi (TI) telah menjadi unsur penting dalam suatu organisasi dan merupakan investasi yang menjadi salah satu pembuat nilai tambah dan keuntungan kompetitif. TI perlu diatur agar dapat dimanfaatkan dengan baik. Tindakan untuk mengatur TI disebut dengan tata kelola TI. Tata kelola TI yang dijalankan dengan baik dapat membantu organisasi dalam upaya mencapai tujuannya.

Ada tiga alasan utama dari upaya penerapan strategi sistem informasi dan teknologi informasi dalam organisasi. Pertama, memperbaiki efisiensi kerja dengan melakukan otomasi berbagai proses yang mengelola informasi. Kedua, meningkatkan keefektifan manajemen dengan memuaskan kebutuhan informasi guna pengambilan keputusan. Ketiga, meningkatkan daya saing atau meningkatkan keunggulan kompetitif organisasi.

Meskipun sistem informasi sudah terkomputerisasi, penggunaan sistem informasi yang terkomputerisasi ini tidak menyebabkan organisasi terlepas dari kecurangan (fraud) dan risiko yang akan dihadapi. Kecurangan dan risiko tersebut dapat berupa kesalahan proses dari program aplikasi, pencurian data, kerusakan data, dll. Untuk memininalkan terjadinya fraud dan risiko dalam sistem informasi maka kebutuhan audit sistem informasi sebagai sarana mengevaluasi pengendalian internal semakin dibutuhkan. Pengendalian Internal tersebut bertujuan untuk mewujudkan efektivitas dan efisiensi operasi, keandalan laporan keuangan, kepatuhan terhadap hukum dan peraturan yang berlaku. Program Kota Tanpa Kumuh (KOTAKU) merupakan program lanjutan dari Program Nasional Pemberdayaan Masyarakat Mandiri Perkotaan (PNPM-MP). Penanganan permukiman kumuh menjadi tantangan yang rumit bagi Pemerintah Kota/Kabupaten, karena selain merupakan masalah, di sisi lain ternyata merupakan salah satu pilar penyangga perekonomian kota. Pengendalian program KOTAKU tingkat pusat dilakukan oleh Konsultan Manajemen Pusat (KMP) sebagai salah satu organisasi yang memiliki jumlah personil konsultan di bawahnya mulai dari tingkatan provinsi sampai dengan tingkatan kelurahan. Tujuan dilakukannya penelitian ini adalah untuk mengukur tingkat kapabilitas dari Sistem Informasi Manajemen KOTAKU di Konsultan Manajemen Pusat. Atas dasar permasalahan diatas, maka perlu dilakukan audit kinerja sistem informasi untuk mengetahui seberapa jauh keselarasan antara proses bisnis, aplikasi, dan strategi bisnis organisasi. Penentuan lokasi penelitian studi kasus tesis di Konsultan Manajemen Pusat karena ditempat tersebut belum pernah melakukan audit khususnya untuk tata kelola teknologi informasi. Audit yang sudah berjalan dalam organisasi KMP ini berupa audit penggunaan anggaran oleh Badan Pemeriksa Keuangan Pusat (BPKP). COBIT 5 dibangun berdasarkan pengembangan dari COBIT 4.1 dengan mengintegrasikan Val IT dan Risk IT dari ISACA, ITIL, dan standar-standar yang relevan dari ISO. Oleh karena itu, maka COBIT 5 merupakan salah satu framework yang cukup diperhitungkan untuk menjadi acuan dalam membuat tata kelola teknologi informasi. Domain yang dipakai dari COBIT 5 yaitu domain DSS (Deliver, Service, and Support). Domain DSS dipilih karena berfokus pada aspek penyampaian teknologi informasi mencakup bidang eksekusi aplikasi di dalam pengiriman dan layanan teknologi informasi serta dukungannya terhadap proses bisnis yang berlangsung termasuk pengelolaan masalah agar keberlanjutan proses bisnis tetap terjaga serta bagaimana mengontrol proses bisnis, mengevaluasi, dan merencanakan secara jangka panjang proses bisnis ke depan.

\section{Landasan Teori}

Definisi Sistem Informasi (SI), Menurut Keneth C. Loudon dan Jane P. Loudon (2007:8) dalam bukunya Management Information System - Managing the digital firm, mengatakan bahwa: Sistem informasi sebagai sekumpulan komponen yang saling berhubungan, mengumpulkan (atau mendapatkan), memproses, menyimpan, dan mendistribusikan informasi untuk menunjang pengambilan keputusan dan pengawasan dalam suatu organisasi. Definisi Teknologi Infromasi (TI), Menurut Thompson dan Cats-Baril (2003, p3) dalam bukunya Information Technology and Management mengatakan bahwa "teknologi informasi adalah perangkat keras dan perangkat lunak yang dikemas sebagai suatu alat untuk menangkap, menyimpan, memproses, dan menghasilkan digital". Pengertian audit menurut Messier, Clover dan Prawitt (2014:12) adalah sebagai berikut: Auditing adalah proses yang sistematik untuk memperoleh dan mengevaluasi bukti secara objektif mengenai asersi-asersi tentang kegiatan dan peristiwa ekonomi untuk menetukan tingkat kesesuaian antara asersi-asersi tersebut dengan kriteria yang ditetapkan dan mengkomunikasikan hasil-hasilnya kepada pihak-pihak yang berkepentingan. Definisi Tata Kelola Teknologi Informasi (IT Governance) yaitu IT Governance merupakan suatu komitmen, kesadaran dan proses pengendalian manajemen organisasi terhadap sumber daya SI/TI yang dibeli dengan harga mahal,

Audit Teknologi Informasi Menggunakan framework COBIT 5 pada Domain DSS ( Deliver, Service and supoort )-( Ricky Perdana Kusuma) 
yang mencakup mulai dari sumber daya komputer (software, brainware, database dan sebagainya) hingga ke Teknologi Informasi dan Jaringan LAN/Internet. Menurut Oltsik (2003:48) mendefinisikan "IT Governance sebagai kumpulan kebijakan, proses/aktivitas dan prosedur untuk mendukung pengoperasian TI agar hasilnya sejalan dengan strategi bisnis (strategi organisasi)". Menurut Fox dan Zonneveld (2004:3135), menyimpulkan dalam tata kelola yang baik peranan IT Governance merupakan hal yang sangat penting, Proses IT Governance dimulai dengan menentukan sasaran untuk IT organisasi/perusahaan, menyediakan petunjuk awal. Setelah itu perulangan secara berkelanjutan dibentuk, kinerja diukur dan dibandingkan dengan sasaran awal, menghasilkan arahan kembali dari aktivitas yang diperlukan dan perubahan sasaran yang sesuai. Ketika sasaran menjadi tanggung jawab utama dan ukuran kinerja manajemen, itu jelas harus dikembangkan dengan perencanaan yang baik sehingga sasaran dapat terjangkau dan ukuran menggambarkan sasaran dengan tepat. COBIT (Control Objectives for Information and Related Technology) adalah suatu panduan standar praktek manajemen teknologi informasi dan sekumpulan dokumentasi best practices untuk tata kelola TI yang dapat membantu auditor, manajemen, dan pengguna untuk menjembatani pemisah (gap) antara risiko bisnis, kebutuhan pengendalian, dan permasalahanpermasalahan teknis. Dalam Cobit 5 Process Assesment Model (PAM) mempunyai 2 area kegiatan utama yaitu: 1. Governance yang meliputi 5 domain proses, berisi tentang Evaluate, Direct, dan Monitoring (EDM) yang telah ditetapkan. Proses EDM ini membahas mengenai objek tata kelola seperti value delivery risk, risk optimization dan resource optimization, termasuk best practice dan aktivitas-aktivitas yang bertujuan untuk mengevaluasi strategis pilihan, menyediakan keluaran arahan pengawasan teknologi informasi. 2. Management of Enterprise IT, dimana domain manajemen TI perusahaan sejalan dengan bidang tanggung jawabnya yaitu Plan, Build, Run dan Monitor (PBRM). Berikut ini keempat domain manajemen: Align, Plan, and Organize (APO), Build, Acquire, and Implemenet (BAI), Deliver, Service, and Support (DSS), dan Monitor, Evaluate, and Asses (MEA). Validitas dan Reliabilitas Menurut (Rostina, 2014), validitas adalah suatu ukuran yang menunjukan tingkat kevalidan atau kesahihan suatu instrument. Suatu instrument dikatakan valid apabila mampu mengukur apa yang diinginkan dan dapat mengungkap data dari variable yang diteliti secara tepat. Uji validitas berguna untuk mengetahui apakah ada pernyataanpernyataan pada kuesioner yang harus dibuang/diganti karena dianggap tidak relevan. Teknik untuk mengukur validitas kuesioner dengan mengkorelasikan antara skor tiap item dengan skor total dan melakukan koreksi terhadap nilai koefisien korelasi yang over estimasi.

\section{Objek dan Metodologi Penelitian}

\subsection{Objek Penelitian}

Konsultan Manajemen Pusat (KMP) bertugas membantu Kepala Satker Pengembangan Kawasan Permukiman Berbasis Masyarakat (PKPBM) atau merupakan satuan kerja di Direktorat Pengembangan Kawasan Permukiman dan berperan sebagai penanggung jawab pelaksanaan National Slum Upgrading Program (NSUP) / Program Kota Tanpa Kumuh (KOTAKU) dan Neighborhood Upgrading and Shelter Project Phase 2 (NUSP-2) yang berkedudukan di Pusat. Dalam hal perencanaan, monitoring dan pelaporan pelaksanaan Program KOTAKU di lapangan yang dilakukan oleh Oversight Consultants (OC)/Oversight Service Provider (OSP). Kantor KMP Wilayah 1 Program KOTAKU beralamat di Jl. Cipaku II No. 12, Kel. Petogogan, Kec. Kebayoran Baru, Jakarta Selatan. Penerapan teknologi informasi di Konsultan Manajemen Pusat mengacu kepada Prosedur Operasional Standar (POS) Sistem Informasi Manajemen (SIM) KOTAKU. POS SIM KOTAKU diperlukan sebagai panduan lengkap yang menjelaskan daya dukung SIM KOTAKU di Konsultan Manajemen Pusat dalam hal membantu pelaksanaan Monitoring dan Evaluasi (Monev). SIM KOTAKU ini sebagai alat pengendalian tidak langsung. Aplikasi SIM KOTAKU di Konsultan Manajemen Pusat dikembangkan dengan satu platform secara terpadu berbasis online dengan acuan utama berdasarkan dari glossary SIM KOTAKU yang disepakati bersama. Glossary sendiri merupakan terjemahan kebutuhan atribut data detil dari kegiatan Program KOTAKU yang tertuang dalam panduan teknis dan target capaian yang tertuang dalam Indikator Capaian Kunci (Key Performance Indicator/KPI) kegiatan Program KOTAKU di Konsultan Manajemen Pusat. Kegiatan pengendalian kualitas dan kelengkapan data SIM KOTAKU menjamin berjalannya aliran data mulai dari pelaku utama melakukan input data di tingkat Kabupaten/Kota (asmandat dan pelaku lainnya), hingga data tersebut sampai ke server database SIM KOTAKU yang ada di pusat. 


\subsection{Metodologi penelitian}

Penelitian tesis ini menggunakan tipe penelitian deskriptif kualitatif. Metode deskriptif dapat diartikan sebagai prosedur pemecahan masalah yang diselidiki dengan menggambarkan keadaan subjek/objek penelitian (seseorang, lembaga, masyarakat dan lain-lain) pada saat sekarang menekankan pada sumber data dan fakta sebagaimana adanya. Data tersebut berasal dari naskah wawancara, catatan lapangan, foto, video tape, dokumen pribadi, catatan atau memo, dan dokumen resmi lainnya. Metode Pengumpulan Data :

1. Data Primer

a. Wawancara

Pengumpulan data yang dilakukan dengan cara berkomunikasi langsung dengan pihak yang mampu memberikan informasi terhadap permasalahan yang sedang diteliti. Penentuan sampel wawancara menggunakan teknik purposive sampling. Menurut Sugiyono (2010:218) purposive sampling adalah "teknik pengambilan sampel sumber data dengan pertimbangan tertentu". Penulis dengan sengaja memilih siapa saja yang akan dijadikan sampel dengan syarat personil yang sudah mempunyai pengalaman kerja lebih dari 5 tahun di Konsultan Manajemen Pusat (KMP) dan mempunyai posisi penting dalam kegiatan organisasi. Hal ini dilakukan supaya penulis mendapatkan gambaran tentang proses kegiatan yang dilaksanakan pada Konsultan Manajemen Pusat terutama pada bagian Sistem Informasi Manajemen KOTAKU lebih jelas serta mengetahui secara lebih rinci bagaimana tata kelola yang selama ini berjalan pada Konsultan Manajemen Pusat.

b. Kuesioner

Pengumpulan data dengan menganalisis hasil kuesioner dengan pihak yang mampu memberikan informasi terhadap permasalahan yang sedang diteliti. Untuk respondennya, penentuan pengambilan data kuesioner ditentukan berdasarkan jabatan dan lama bertugas di KMP lebih dari 5 tahun.

c. Observasi

Pengumpulan data melalui pengamatan dan pencatatan data secara langsung di lapangan terhadap proses yang terjadi.

2. Data Sekunder

a. Studi Pustaka

Metode pengumpulan data dengan mencari data kepustakaan berupa buku, jurnal ilmiah, e-book, dan lain sebagainya yang ada kaitannya dengan penelitian.

b. Rencana Stretegis dan Rencana jangka panjang KMP.

Data diperoleh dari penjelasan dan penjabaran rencana strategis KMP dalam kurun waktu tertentu dan telah ditentukan sehingga memudahkan dalam pengklasifikasian terhadap masalah yang diteliti.

\subsection{Tahap Analisa}

Pada tahap analisa ini menjelaskan bagaimana proses pelaksanaan audit secara detail, yaitu :

1. Menentukan kebutuhan stakeholder yang berhubungan dengan tujuan umum Konsultan Manajemen Pusat.

2. Identifikasi tujuan strategis Konsultan Manajemen Pusat, lalu dilakukan analisa antara tujuan strategis Konsultan Manajemen Pusat dengan Balance Scorecard Perspektif (BSC).

3. Identifikasi Enterprise Goals terpilih lalu dilakukan analisa keterhubungan antara tujuan strategis Konsultan Manajemen Pusat dan Enterprise Goals pada COBIT 5.

4. Melakukan scoping terhadap analisis tata kelola IT di KMP, dengan cara mengidentifikasi tujuan organisasi yang akan diselaraskan dengan Enterprise Goals pada COBIT 5, lalu dilakukan scoring. Hasil scoring tersebut akan diturunkan menjadi IT Related Goals pada COBIT 5 yang memiliki keterhubungan dengan Enterprise Goals terpilih, sehingga menghasilkan proses TI terpilih.

5. Mengumpulkan data terkait penelitian melalui proses wawancara, kuesioner, dan observasi kepada responden yang terkait dan relevan dengan penelitian.

6. Menilai capability level pada setiap proses TI terpilih. Penilaian proses TI bertujuan untuk menentukan tingkat performansi dari setiap proses.

7. Menentukan target capability level yang diharapkan pada setiap proses TI pada domain DSS (Deliver, Service, and Support).

8. Melakukan analisa GAP (kesenjangan) antara capability level saat ini dengan capability level yang diharapkan. 
9. Memberikan rekomendasi untuk proses TI untuk dapat mencapai capability level harapan berdasarkan hasil analisa kesenjangan.

10. Menarik kesimpulan dan membuat saran.

\subsection{Alur Penelitian}

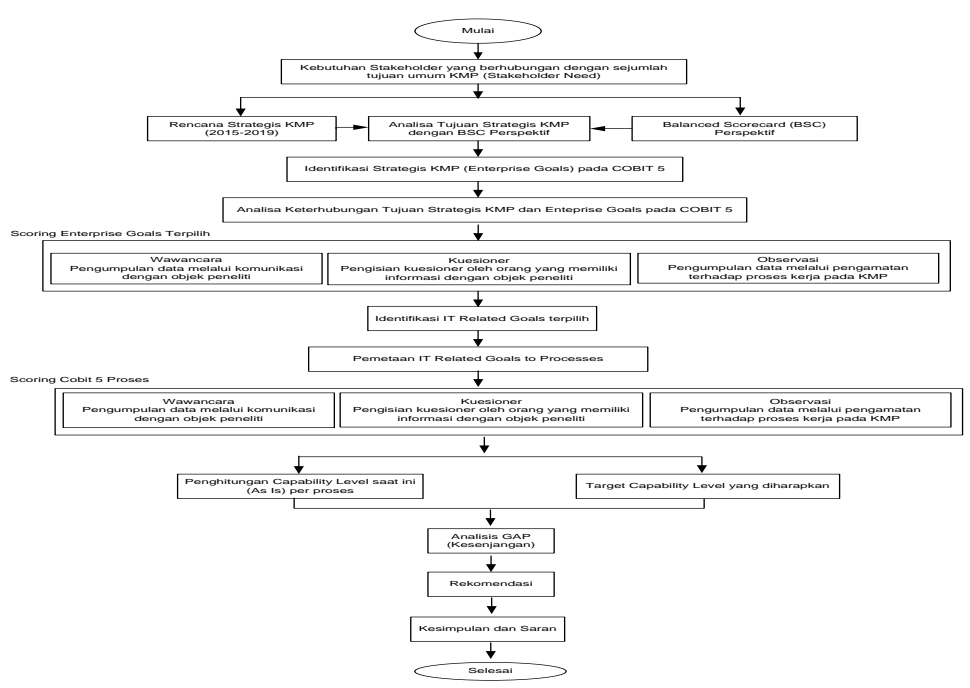

Gambar.1 Alur penelitian

\section{Analisa dan Pembahasan}

\subsection{Identifikasi Tujuan Strategis Konsultan Manajemen Pusat (KMP)}

Pada tahap identifikasi tujuan strategis diperlukan penggalian data kebutuhan stakeholder (Stakeholder Need) yang berhubungan dengan sejumlah tujuan umum organisasi dianalisis menggunakan empat perspektif Balanced Scorecard (BSC). Empat perspektif tersebut antara lain Financial Perspective, Customer Perspective, Internal Process Perspective, dan Learning and Growth Perspective.

\subsection{Identifikasi Enterprise Goals Terpilih Pada COBIT 5}

Pada tahap ini, tujuan strategis Konsultan Manajemen Pusat (KMP) akan diselaraskan dengan Enterprise Goals dalam COBIT 5. Enterprise Goals dalam COBIT 5 terdiri dari 17 Enterprise goals. Selanjutnya dilakukan identifikasi adanya keterhubungan antara setiap tujuan strategis Konsultan Manajemen Pusat dengan Enterprise Goals untuk mendapatkan Enterprise Goals terpilih. Hasil pemetaan Enterprise Goals terpilih yang ada keterhubungan dengan rencana strategis KMP ada 6 item yaitu (EG6, EG9, EG12, EG14, EG15, EG16), untuk Enterprise Goals yang tidak memiliki keterhubungan dengan strategis KMP ada 11 item yaitu (EG1, EG2, EG3, EG4, EG5, EG7, EG8, EG10, EG11, EG13, EG17).

\subsection{Scoring Proses Terpilih Pada COBIT 5}

Pada tahap ini, akan dilakukan pemberian score terhadap Enterprise Goals terpilih, sesuai dengan tujuan strategis Konsultan Manajemen Pusat. Pemberian score ini dilakukan oleh beberapa responden, di bawah ini menampilkan data responden: 
Tabel .1 Data Responden

\begin{tabular}{|c|l|l|c|}
\hline No & $\begin{array}{c}\text { Kode } \\
\text { Responden }\end{array}$ & \multicolumn{1}{|c|}{ Responden } & $\begin{array}{c}\text { Jumlah } \\
\text { Responden }\end{array}$ \\
\hline 1 & TL & NMC Team Leader & 1 \\
\hline 2 & TA UP & $\begin{array}{l}\text { Tenaga Ahli Urban } \\
\text { Planning }\end{array}$ & 1 \\
\hline 3 & TA MKL & $\begin{array}{l}\text { Financial Management } \\
\text { \& Livelihood Spesialist }\end{array}$ & 1 \\
\hline 4 & TA Infra & $\begin{array}{l}\text { Infrastructure } \\
\text { Spesialist }\end{array}$ & 1 \\
\hline 5 & TA SIM & $\begin{array}{l}\text { Data Management } \\
\text { Spesialist }\end{array}$ & 1 \\
\hline 6 & TA Train & Training Spesialist & 1 \\
\hline 7 & TA Monev & $\begin{array}{l}\text { Program Management } \\
\text { Spesialist }\end{array}$ & 1 \\
\hline
\end{tabular}

\subsection{Identifikasi IT-Related Goals Terpilih}

Identifikasi selanjunya akan ditentukan IT-Related Goals yang terpilih sesuai dengan Enterprise Goals menggunakan tabel Mapping COBIT 5 Enterprise Goals to IT-Related Goals yang terdapat dalam Appendix B COBIT 5. Di bawah ini merupakan hasil pemetaan Enterprise Goals dengan IT-Related. Di bawah ini adalah hasil dari pemetaannya:

Tabel 2 Pemetaan Enterprise Goals dengan IT-Related Goals

\begin{tabular}{|r|l|c|c|}
\hline \multirow{2}{*}{ No } & \multirow{2}{*}{$\begin{array}{c}\text { Kode } \\
\text { Enterprise } \\
\text { Goals }\end{array}$} & \multicolumn{2}{|c|}{$\begin{array}{c}\text { Mapping COBIT 5 } \\
\text { Enterprise Goals to IT - } \\
\text { Related Goals }\end{array}$} \\
\cline { 3 - 5 } & keterhubungan & $\begin{array}{c}\text { Ada-Related } \\
\text { Goals }\end{array}$ \\
\hline 1 & EG6 & $v$ & 1,7 \\
\hline 2 & EG9 & $v$ & 1,14 \\
\hline 3 & EG12 & $v$ & $5,6,11$ \\
\hline 4 & EG14 & $v$ & 8,16 \\
\hline 5 & EG15 & $v$ & $2,10,15$ \\
\hline 6 & EG16 & $v$ & 16 \\
\hline
\end{tabular}

\subsection{Identifikasi Proses Terpilih COBIT 5}

Berdasarkan IT-Related Goals terpilih, langkah selanjutnya adalah menentukan COBIT 5 proses yang terpilih sesuai dengan IT-related Goals terpilih menggunakan Tabel Mapping COBIT 5 IT-Related Goals to Processes yang terdapat dalam Appendix C COBIT 5. 
Tabel 3 Mapping COBIT 5 IT-Related Goals to Processes

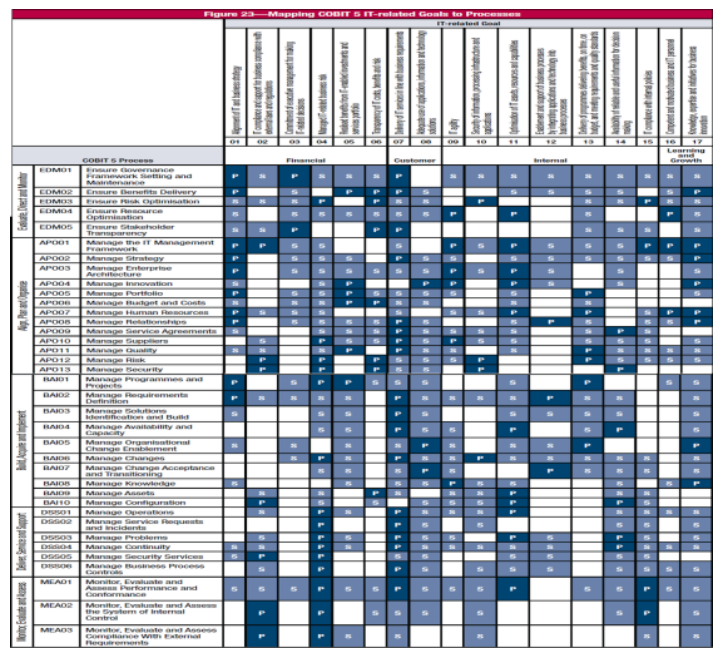

Sumber : (Cobit 5, 2012)

Tabel 4. Pemetaan IT-Related Goals to Processes

\begin{tabular}{|c|c|c|}
\hline No & $\begin{array}{l}\text { Kode IT- } \\
\text { Related } \\
\text { Goals }\end{array}$ & Cobit 5 Process \\
\hline 1 & IT-G1 & $\begin{array}{c}\text { EDM01, EDM02, APO01, } \\
\text { APO02, APO03, APO05, } \\
\text { APO07, APO08, BAI01, } \\
\text { BAI02 }\end{array}$ \\
\hline 2 & IT-G2 & $\begin{array}{c}\text { APO01, APO12, APO13, } \\
\text { BAl10, DSS05, MEA02, } \\
\text { MEA03 }\end{array}$ \\
\hline 3 & IT-G5 & $\begin{array}{l}\text { EDM02, APO04, APO05, } \\
\text { APO06, APO11, BAI01 }\end{array}$ \\
\hline 4 & IT-G6 & $\begin{array}{l}\text { EDM02, EDM03, EDM05, } \\
\text { APO06, APO12, APO13, } \\
\text { BAI09 }\end{array}$ \\
\hline 5 & IT-G7 & $\begin{array}{l}\text { EDM01, EDM02, EDM05, } \\
\text { APO02, APO08, APO09, } \\
\text { APO10, APO11, BAI02, } \\
\text { BAI03, BAI04, BAI06, } \\
\text { DSS01, DSS02, DSS03, } \\
\text { DSS04, DSS06, MEA01 }\end{array}$ \\
\hline 6 & IT-G8 & APO04, BAI05, BAI07 \\
\hline 7 & IT-G10 & $\begin{array}{c}\text { EDM03, APO12, APO13, } \\
\text { BAI06, DSS05 }\end{array}$ \\
\hline 8 & IT-G11 & $\begin{array}{c}\text { EDM04, APO01, APO03, } \\
\text { APO04, APO07, BAI04, } \\
\text { BAI09, BAl10, DSS01, } \\
\text { DSS03, MAE01 }\end{array}$ \\
\hline 9 & IT-G14 & $\begin{array}{l}\text { APO09, APO13, BAI04, } \\
\text { BAl10, DSS03, DSS04 }\end{array}$ \\
\hline 10 & IT-G15 & $\begin{array}{l}\text { EDM03, APO01, MEA01, } \\
\text { MEA02 }\end{array}$ \\
\hline 11 & IT-G16 & EDM04, APO01, APO07 \\
\hline
\end{tabular}




\subsection{Hasil COBIT 5 Process Terpilih Sesuai Scoring Pada Domain DSS}

COBIT 5 Process terpilih yang akan dijadikan objek penelitian tesis ini yaitu pada Domain DSS (Deliver, Service, and Support) akan diberikan scoring oleh responden berdasarkan tahapan berikut ini:

1. COBIT 5 Process terpilih akan diberikan score berdasarkan kepentingan strategis KMP dimana pelayanan, permasalahan, keamanaan dan inovasi penerapan teknologi informasi.

2. Scoring berdasarkan tingkat kepentingan, dapat dilihat pada Table 4.13 di bawah ini:

Tabel 5 Scoring Berdasarkan Tingkat Kepentingan

\begin{tabular}{|c|c|c|}
\hline No & Score & Tingkat Kepentingan \\
\hline 1 & $1-2$ & Tidak Penting \\
\hline 2 & $3-4$ & Sedikit Penting \\
\hline 3 & $5-6$ & Cukup Penting \\
\hline 4 & $7-8$ & Penting \\
\hline 5 & $9-10$ & Sangat Penting \\
\hline
\end{tabular}

3. Dalam proses COBIT 5 yang terpilih adalah proses yang memiliki score lebih besar sama dengan ( $\geq) 7$.

Tabel 6 Scoring COBIT 5 Process

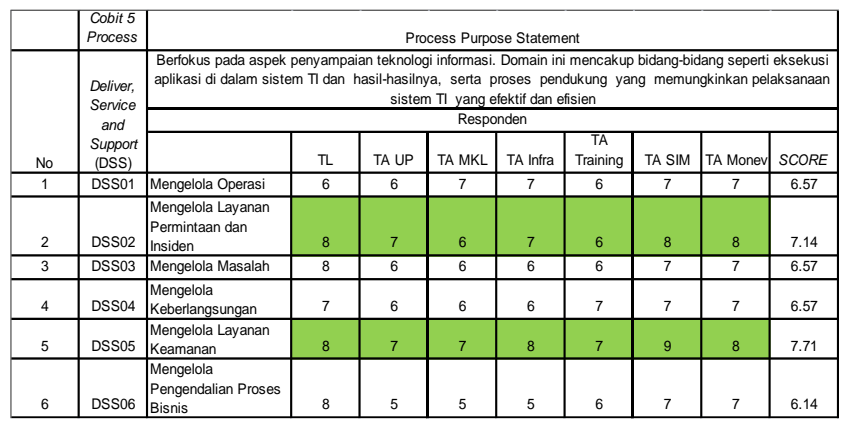

Dari tahapan-tahapan di atas, didapatkan proses dalam COBIT 5 terpilih pada Domain DSS seperti pada

Tabel 4.7 berikut ini:

Tabel 7 Proses COBIT 5 Terpilih Sesuai Scoring

\begin{tabular}{|c|l|l|}
\hline No & $\begin{array}{l}\text { COBIT 5 } \\
\text { Process }\end{array}$ & \multicolumn{1}{|c|}{ Deskripsi } \\
\hline 1 & DSS02 & $\begin{array}{l}\text { Mengelola Layanan } \\
\text { Permintaan dan Insiden }\end{array}$ \\
\hline 2 & DSS05 & $\begin{array}{l}\text { Mengelola Layanan } \\
\text { Keamanan }\end{array}$ \\
\hline
\end{tabular}

\subsection{Pengelolaan Data Kuesioner}

Dalam penelitian tesis ini penulis menggunakan metode kuesioner dengan berpedoman pada Proses Assessment Model (PAM) dan Capability Model COBIT 5 yaitu dengan melihat point-point aktivitas pada setiap domain untuk menentukan tingkat kapabilitas. Kuesioner yang akan dilakukan untuk mengetahui tingkat kapabilitas pengelolaan sistem informasi yaitu berupa pertanyaan-pertanyaan. Sebelum mengolah hasil kuesioner, dilakukan uji validitas. Uji validitas diperlukan untuk mengukur seberapa besar kesesuaian pemahaman antara peneliti dengan responden mengenai pertanyaan-pertanyaan yang diberikan. 
Perhitungan ini dilakukan dengan tujuan mengukur ke absahan dari pertanyaan- pertanyaan kuesioner. Pengelolaan data uji menggunakan software Microsoft Excel. Uji validitas yang digunakan menggunakan korelasi.

\subsubsection{Uji Validitas DSSO2}

Pada domain DSS02 ini, terdapat 7 proses yang harus dilakukan uji validitas dari hasil kuesioner yang dilakukan. Berikut ini hasil dari uji validitas dalam bentuk tabel.

Tabel 8 Validitas DSS02.01

\begin{tabular}{|c|c|c|c|c|c|c|c|}
\hline \multirow[b]{2}{*}{ DSS02.01 } & \multicolumn{7}{|c|}{ Pertanyaan } \\
\hline & \multicolumn{5}{|c|}{ Aktivitas } & Output & \multirow[b]{2}{*}{ Total Skor } \\
\hline Responden & & & & & & & \\
\hline 1 & & & & & & I & $\begin{array}{l}1 \quad 5 \\
\end{array}$ \\
\hline 2 & & & & & & r & 2 \\
\hline 3 & & & & & & t & 2 \\
\hline 4 & & & & & & I & 5 \\
\hline 5 & & & & & & Tra & 4 \\
\hline 6 & & & & & & 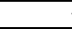 & 6 \\
\hline 7 & & & & & & I & 6 \\
\hline r (Hitung) & 0.591 & 0.591 & 0.515 & 0.916 & 0.34 & 0.706 & 30 \\
\hline r kritis & 0.3 & 0.3 & 0.3 & 0.3 & 0.3 & 0.3 & \\
\hline Validitas & Valid & Valid & Valid & Valid & Valic & Valid & \\
\hline $\mathrm{R}$ (Hitung) & \multicolumn{6}{|c|}{0.61} & \\
\hline R kritis & \multicolumn{6}{|c|}{0.6} & \\
\hline Reabilitas & \multicolumn{6}{|c|}{ Reliabel } & \\
\hline
\end{tabular}

Tabel 9 Validitas DSS02.02

\begin{tabular}{|c|c|c|c|c|c|}
\hline \multirow[b]{2}{*}{ DSS02.02 } & \multicolumn{5}{|c|}{ Pertanyaan } \\
\hline & \multicolumn{3}{|c|}{ Aktivitas } & Output & \multirow[b]{2}{*}{ Total Skor } \\
\hline Responden & 1 & 2 & 3 & 4 & \\
\hline 1 & 1 & 1 & 0 & 0 & $\begin{array}{r}2 \\
\end{array}$ \\
\hline 2 & 0 & 0 & 1 & 0 & 1 \\
\hline 3 & 1 & 1 & 0 & 1 & 3 \\
\hline 4 & 0 & 1 & 0 & 0 & 1 \\
\hline 5 & 1 & 1 & 1 & 1 & 4 \\
\hline 6 & 0 & 0 & 1 & 1 & 2 \\
\hline 7 & 1 & 1 & 1 & 1 & 4 \\
\hline$r$ (Hitung) & 0.805 & 0.499 & 0.315 & 0.805 & 17 \\
\hline r kritis & 0.3 & 0.3 & 0.3 & 0.3 & \\
\hline Validitas & Valid & Valid & Valid & Valid & \\
\hline R (Hitung) & \multicolumn{4}{|c|}{0.606} & \\
\hline R kritis & \multicolumn{4}{|c|}{0.6} & \\
\hline Reabilitas & \multicolumn{4}{|c|}{ Reliabel } & \\
\hline
\end{tabular}


Tabel 10. Validitas DSS02.06

\begin{tabular}{|c|c|c|c|c|c|}
\hline \multirow{3}{*}{$\begin{array}{r}\text { DSS02.06 } \\
\text { Responden } \\
\end{array}$} & \multicolumn{5}{|c|}{ Pertanyaan } \\
\hline & \multicolumn{2}{|c|}{ Aktivitas } & \multicolumn{2}{|c|}{ Output } & \multirow[b]{2}{*}{ Total Skor } \\
\hline & 1 & 2 & 3 & 4 & \\
\hline 1 & 0 & 0 & 1 & 1 & 2 \\
\hline 2 & 0 & 0 & 0 & 0 & 0 \\
\hline 3 & 1 & 1 & 1 & 1 & 4 \\
\hline 4 & 0 & 1 & 0 & 0 & 1 \\
\hline 5 & 1 & 1 & 1 & 1 & 4 \\
\hline 6 & 0 & 0 & 0 & 1 & 1 \\
\hline 7 & 1 & 1 & 1 & 1 & 4 \\
\hline$r$ (Hitung) & 0.941 & 0.706 & 0.889 & 0.716 & 16 \\
\hline$r$ kritis & 0.3 & 0.3 & 0.3 & 0.3 & \\
\hline Validitas & Valid & Valid & Valid & Valid & \\
\hline R (Hitung) & \multicolumn{4}{|c|}{0.813} & \\
\hline R kritis & \multicolumn{4}{|c|}{0.6} & \\
\hline Reabilitas & \multicolumn{4}{|c|}{ Reliabel } & \\
\hline
\end{tabular}

Tabel 11. Validitas DSS02.07

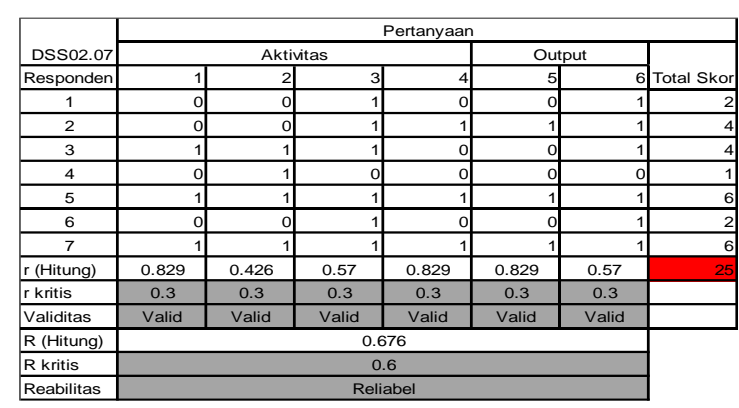

\subsubsection{Uji Validitas DSS05}

Pada domain DSS05 ini, terdapat 7 proses yang harus dilakukan uji validitas dari hasil kuesioner yang dilakukan. Berikut ini hasil dari uji validitas dalam bentuk tabel.

Tabel 12. Validitas DSS05.01

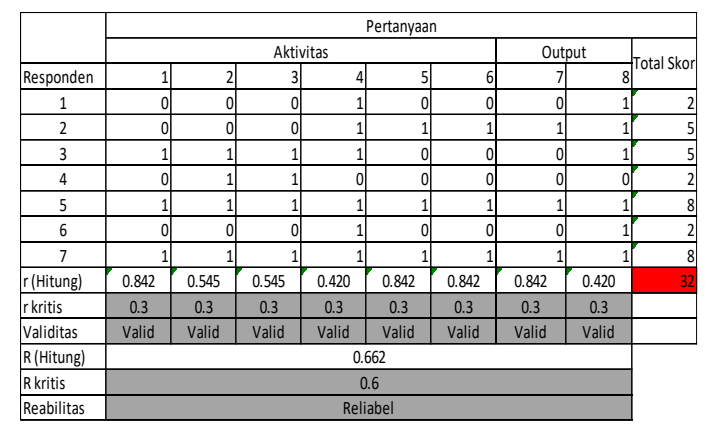

Audit Teknologi Informasi Menggunakan framework COBIT 5 pada Domain DSS ( Deliver, Service and supoort )-( Ricky Perdana Kusuma) 


\subsection{Kapabilitas dan GAP}

Berdasarkan hasil dari proses assessment, maka kebijakan yang diambil pada Konsultan Manajmen Pusat (KMP) masih ada pada level 1, dimana target yang diinginkan oleh pihak manajemen yaitu berada pada level 2 dengan pertimbangan karena penerapan baru 2 tahun untuk SIM KOTAKU di KMP.

Tabel 15. Hasil Assessment

\begin{tabular}{|l|l|c|c|c|c|c|c|}
\hline $\begin{array}{c}\text { Process ID DSS } \\
\text { (Deliver, Service, } \\
\text { and Support) }\end{array}$ & Process Name & Level 0 & Level 1 & Level 2 & Level 3 & Level 4 & Level 5 \\
\hline DSS02 & $\begin{array}{l}\text { Manage Service } \\
\text { Requests and } \\
\text { Incidents }\end{array}$ & & F & L & & & \\
\hline DSS05 & $\begin{array}{l}\text { Manage Security } \\
\text { Serices }\end{array}$ & & F & L & & & \\
\hline
\end{tabular}

Analisis gap dilakukan untuk mencari selisih dari level kapabilitas yang didapat dengan level target yang ingin dicapai. Dalam penentuan level target, ditentukan dengan level yang sedang dituju dari level yang didapat sekarang. Berikut ini hasil analisa gapnya:

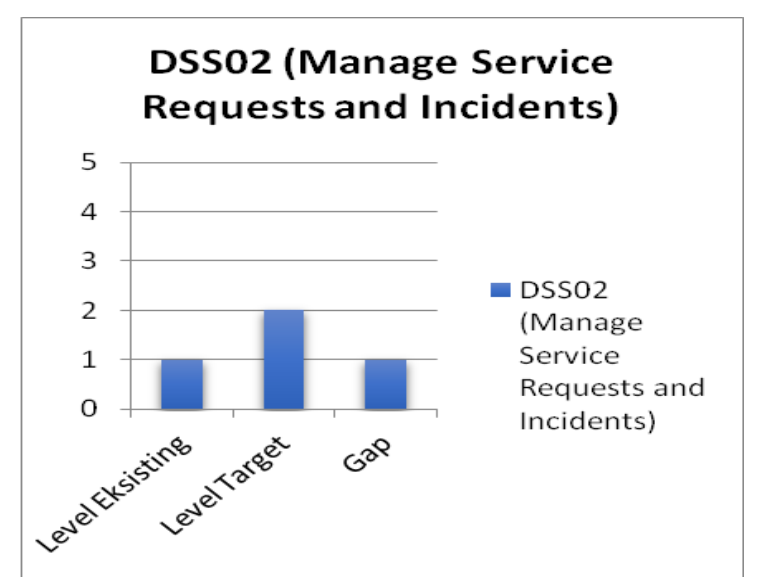

Gambar 2. Analisa Gap

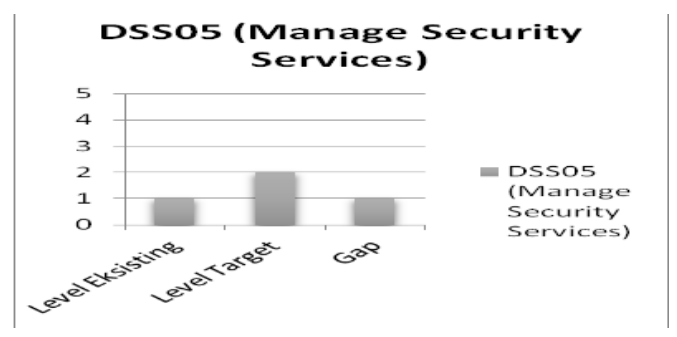

Gambar 3. Analisa manage security services

\subsection{Rekomendasi}

Berdasarkan dari hasil proses assessment yang telah dilakukan pada penelitian diatas, maka ada beberapa rekomendasi yang dapat disarankan pada manajemen Komsultan Manajemen Pusat (KMP), yaitu: 1. Rekomendasi untuk Domain DSS02 
Berdasarkan analisis Gap yang di dapat dengan level target yang ingin dicapai pada DSS02, berikut adalah beberapa rekomendasi yang dapat diberikan untuk meningkatkan kualitas pengelolaan layanan permintaan dan insiden SIM KOTAKU di KMP:

a. Membuat klasifikasi terhadap jenis-jenis layanan dan insiden yang dilayani, sehingga mudah untuk dipetakan ke bagian atau divisi yang akan langsung menyelesaikan layanan atau insiden tersebut.

b. Membuat strategi-strategi dalam permintaan layanan dan pemecahan insiden baik dalam bentuk kebijakan ataupun tindakan penanganan langsung seperti sistem.

c. Melakukan review terhadap SOP (Standard Operating Procedure) yang dibuat minimal tiap satu tahun untuk mengetahui ketidaksesuaian yang terjadi dan melakukan inovasi terhadap SOP yang sudah ada.

d. Memberikan wadah untuk kritik dan saran kepada user pengguna untuk menilai pelayanan, kepuasan pengguna dan pengembangannya

2. Rekomendasi untuk Domain DSS05

Berdasarkan analisis Gap yang di dapat dengan level target yang ingin dicapai pada DSS05, maka berikut adalah beberapa rekomendasi yang dapat diberikan untuk meningkatkan kualitas pengelolaan layanan keamanan SIM KOTAKU di KMP:

a. Membuat kebijakan terkait dengan software malware, didokumentasikan dan dievaluasi. (misalnya: menginstall antivirus yang diwajibkan)

b. Menetapkan sistem yang digunakan untuk mengevaluasi ancaman-ancaman yang akan timbul, didokumentasikan dan dimonitoring.

c. Melakukan evaluasi yang dilakukan rutin, minimal tiap semester terhadap sistem informasi yang dikhawatirkan dapat timbul potensi ancaman baru.

d. Memberikan peringatan kepada semua pegawai akan kedasarannya terhadap keamanan sistem dan perangkat yang dimiliki.

\section{Kesimpulan dan Saran}

Berdasarkan hasil dari audit TI yang dilakukan pada Konsultan Manajemen Pusat (KMP) untuk Sistem Informasi Manajemen KOTAKU, dapat disimpulkan dan diberikan beberapa saran untuk perbaikan ke depannya.

\subsection{Kesimpulan}

Audit TI yang dilakukan pada Konsultan Manajemen Pusat (KMP) untuk SIM KOTAKU dengan framework COBIT 5 Domain DSS (Deliver, Service, and Support) maka kesimpulan dari tesis ini adalah:

1. Pada tahap scoring COBIT 5, diperoleh 2 proses domain yaitu DSS02 (Pengelolaan Layanan Permintaan dan Insiden) dan DSS05 (Pengelolaan Layanan Keamanan) dimana merupakan hasil scoring berdasarkan tingkat kepentingan yang terpilih adalah proses yang memiliki score lebih besar sama dengan $(\geq) 7$.

2. Dari hasil audit diketahui bahwa untuk 2 proses domain DSS02 dan DSS05 mempunyai level kapabilitas 1 (Performed Process)

3. Menurut level kapabilitas masing-masing proses ditentukan level target masing-masing proses yaitu berupa 1 level di atas level kapabilitas, yang ditentukan berdasar analisis dan juga persetujuan dengan stakeholder, sehingga didapat level target untuk DSS02 dan DSS05 adalah level 2 (Managed Process).

4. Level capability keseluruhan yang diperoleh berdasarkan keseluruhan rata-rata adalah level 1 (Performed Process) yang berarti sebagian besar proses yang diimplementasikan pada domain DSS untuk SIM KOTAKU di KMP telah sesuai dengan yang ditentukan. 


\subsection{Saran}

Berikut adalah saran yang dapat disampaikan dalam tesis ini adalah:

1. Hasil dari penilaian tingkat kapabilitas ini segera mungkin dapat ditindaklanjuti oleh stakeholder untuk dijadikan bahan evaluasi dalam perbaikan Sistem Informasi Manajemen KOTAKU di Konsultan Manajemen Pusat (KMP).

2. Untuk mencapai level yang lebih tinggi diperlukan adanya langkah strategis dalam pemenuhan standar dalam melakukan proses tersebut, terdokumentasi dan komunikasi berjalan dengan baik.

3. Penilaian tingkat kapabilitas terkait SIM KOTAKU di Konsultan Manajemen Pusat (KMP) dalam tesis ini dapat dilanjutkan lagi pada domain-domain lain menggunakan COBIT 5.

4. Metode dalam penghitungan validasi dan penentuan level capability tiap aktifitas dapat dilakukan dengan metode yang berbeda.

\section{Daftar Pustaka}

[1] Cat-Baril, W., Thompson, R. 2003. Information Technology and Management, McGraw-Hill, New York.

[2] Fox, Christopher dan Zonneveld, Paul., 2004, IT Control Objectives for Sarbanes, Information system Audit and Control Association.

[3] ISACA. 2012. COBIT 5: A Business Framework for the Governance and Management of Enterprise IT, ISACA. Available at: www.isaca.org.

[4] ISACA. 2012. COBIT 5: Enabling Process, ISACA. Available at: www.isaca.org.

[5] ISACA. 2012. COBIT 5 Toolkit: COBIT and GRC, ISACA. Available at: www.isaca.org.

[6] ISACA. 2012. COBIT 5 Process Assesment Model-PAM. ISACA. Available at: www.isaca.org.

[7] ISACA. 2013. Mapping to COBIT 5.

[8] Laudon, Kenneth C and Laudon, Jane P,.2007. Management Information System - Managing The Digital System, Penerbit Salemba Empat.

[9] Messier, William F., Steven M. Glover, Douglas F. Prawitt. 2014. Jasa Audit dan Assurance. Edisi 8, Selemba Empat, Jakarta.

[10] Oltsik, Jon., 2003. IT Governance : Is IT Governance the Answer?In : Tech Republic, Januaril3. Pedoman Teknis KOTAKU. 2016. 